\title{
Busy Bees: Variation in Insect Flower-Visiting Rates across Multiple Plant Species
}

\author{
Margaret J. Couvillon, ${ }^{1}$ Chandra M. Walter, ${ }^{1}$ Eluned M. Blows, ${ }^{1}$ Tomer J. Czaczkes, ${ }^{1,2}$ \\ Karin L. Alton, ${ }^{1}$ and Francis L. W. Ratnieks ${ }^{1}$ \\ ${ }^{1}$ Laboratory of Apiculture and Social Insects (LASI), School of Life Sciences, University of Sussex, Falmer, Brighton BN1 9QG, UK \\ ${ }^{2}$ Biologie I, Universität Regensburg, 93053 Regensburg, Germany \\ Correspondence should be addressed to Margaret J. Couvillon; maggiejanec@gmail.com
}

Received 12 December 2014; Revised 18 May 2015; Accepted 26 May 2015

Academic Editor: Bertrand Schatz

Copyright (C) 2015 Margaret J. Couvillon et al. This is an open access article distributed under the Creative Commons Attribution License, which permits unrestricted use, distribution, and reproduction in any medium, provided the original work is properly cited.

\begin{abstract}
We quantified insect visitation rates by counting how many flowers/inflorescences were probed per unit time for five plant species (four native and one garden: California lilac, bramble, ragwort, wild marjoram, and ivy) growing in Sussex, United Kingdom, by following individual insects $(n=2987)$ from nine functional groups (honey bees (Apis mellifera), bumble bees (Bombus spp.), hoverflies, flies, butterflies, beetles, wasps, non-Apidae bees, and moths). Additionally, we made a census of the insect diversity on the studied plant species. Overall we found that insect groups differed greatly in their rate of flower visits $\left(P<2.2 e^{-16}\right)$, with bumble bees and honey bees visiting significantly more flowers per time (11.5 and 9.2 flowers/minute, resp.) than the other insect groups. Additionally, we report on a within-group difference in the non-Apidae bees, where the genus Osmia, which is often suggested as an alternative to honey bees as a managed pollinator, was very speedy (13.4 flowers/minute) compared to the other non-Apidae bees ( 4.3 flowers/minute). Our census showed that the plants attracted a range of insects, with the honey bee as the most abundant visitor (34\%). Therefore, rate differences cannot be explained by particular specializations. Lastly, we discuss potential implications of our conclusions for pollination.
\end{abstract}

\section{Introduction}

Many factors, both plant- and insect-centered, can affect pollination. From the plant perspective, these may include quality, quantity, and temporal/spatial variation of pollen production and the receptivity of the stigma [1-13]. Because insect pollination is a generally indirect effect of foraging behavior (with some well-known exceptions), plants have also evolved adaptations that influence pollinating insects, such as providing rewards, developing nectar guides to help direct pollinator movement, and placing the rewards so that the pollinator must contact the stamens or stigma [14].

In addition, pollinating insects themselves also have various attributes that affect their efficacy as pollinators, such as how much pollen they typically collect on their bodies $[15,16]$ and their degree of flower constancy [17]. Another important factor contributing to pollination is the movement of pollinators between flowers, where a higher visitation rate should result in a greater amount of pollination, if all else is equal.

Previously, flower visitation rate has been mostly investigated from the plant perspective, where researchers quantify visits by different pollinators to a particular plant $[2,18-$ 26]. However, any variation in visitation rate among different pollinators on a particular plant species may reflect a specialization or advantage of that particular pollinator-plant pair, such as the proficiency of hummingbirds on larkspur (compared to bumble bees) or bumble bees on lavender (compared to honey bees $[19,27])$. What is less known is whether there are general, broadly consistent differences in the visitation rate between insect functional groups. In other words, we wished to know more about flower visitation rates from the perspective of the insect across different flowering plants. 


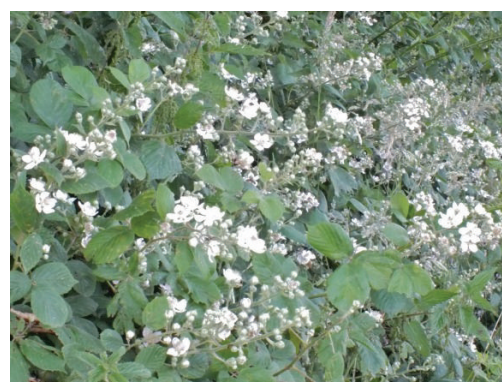

(a)

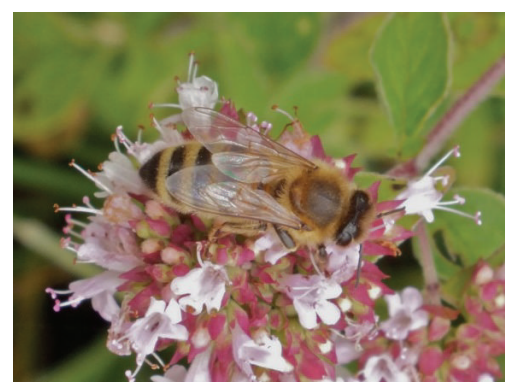

(d)

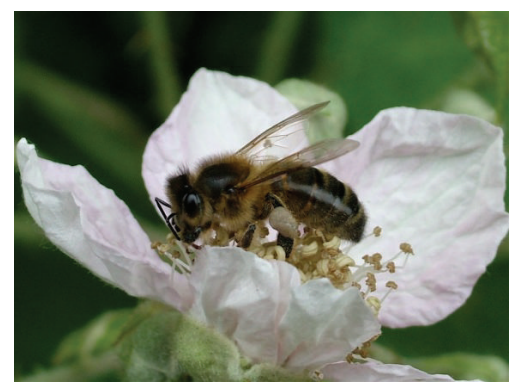

(b)

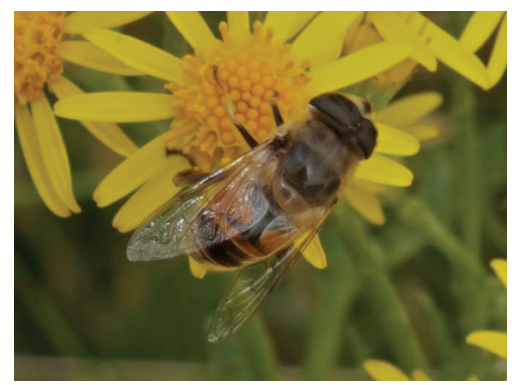

(e)

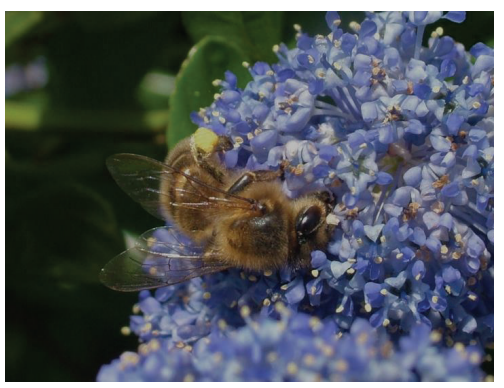

(c)

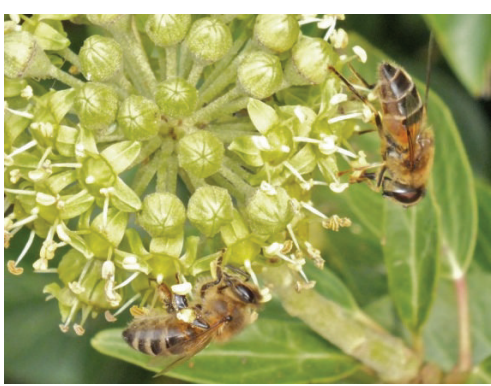

(f)

FIGURE 1: We investigated insect visitation rate on five plant study species: bramble (Rubus fruticosus (a), (b)), California lilac (Ceanothus spp. (c)), marjoram (Origanum vulgare (d)), ragwort (Jacobaea vulgaris (e)), and ivy (Hedera helix and H. hibernica spp. (f)). Other than California lilac, a garden shrub, all plants are native to the study area and all five plants were abundant and found in large patches (a). All insects seen are honey bees, with the exception of the similar-sized hoverfly Eristalis spp. on ragwort in (e) and on the right on ivy in (f) (insect on the left in (f) is honey bee).

\section{Materials and Methods}

2.1. Study Locations, Plants, and Insect Identification. Our data were collected at six different locations in southeast England (Albury Downs, Surrey; Ardingly, West Sussex; Herstmonceux, East Sussex; Falmer, East Sussex; Wivelsfield, East Sussex; Magham Down, East Sussex). Our goal was to collect rate and census data of insects foraging on each plant species from a minimum of two locations. Locations growing the same plant may differ in microclimate (e.g., different sunshine or wind exposure or soil type) and other factors (e.g., proximity to a nesting aggregation of a particular insect type), so we retained location as a random factor within the model (see below for details).

We studied insect visitation on five plants (Figure 1): bramble (Rubus fruticosus), California lilac (Ceanothus spp.), marjoram (Origanum vulgare), ragwort (Jacobaea vulgaris), and ivy (Hedera helix and H. hibernica). All except Ceanothus, a shrub native to California and commonly grown in UK gardens, were native. We studied a number of plant species because we wanted to know whether there were general differences among insects in visitation rates. We chose plants that were in abundance at different locations, were highly attractive to insects, and were attracting a variety of insect types.

Flower morphology and the arrangement of flowers in inflorescences vary between plants (Figure 1). As we were interested in relative differences between insects across plants, the manner in which flower visits were counted needed only to be consistent within plant type, irrespective of insect. Therefore, we defined "flower visit" in a way that was practical and ecologically relevant for each plant. For bramble, each flower is large (diameter c. $3 \mathrm{~cm}$ ), and it is possible to identify insect visits to individual flowers (Figure 1(b)). Because ragwort (Asteraceae) has distinct composite flowers (capitulum, diameter c. $2 \mathrm{~cm}$; Figure 1(e)), we considered a capitulum visit to be the measurement unit. Lastly, California lilac, marjoram, and ivy all possess small flowers (diameter $\mathrm{c}$. few millimeters; Figures 1(c), 1(d), and 1(f)) clustered tightly into inflorescences. For these, we found it impractical to quantify visits to individual flowers and instead defined a flower visit as an inflorescence visit.

Because some of our data were collected by nonexpert insect enthusiasts, we were limited in our taxonomic resolution. Some insects could be identified to species (e.g., honey bees, bumble bees, and butterflies), even in the field as they foraged. However, as we did not collect the insects for later identification, others (hoverflies of the genus Eristalis, many of the non-Apidae bees) proved more difficult. Therefore, although we recorded species if it were known, we confined our analysis to nine broad functional groups: honey bees, bumble bees (Bombus spp.), butterflies, hoverflies, nonApidae bees, beetles, flies (nonhoverflies), moths, and wasps. All of the rate data (flowers/minute) were collected on insects that fall within these groups. The census data (see below) used the same groups, with the exception of moths, which 


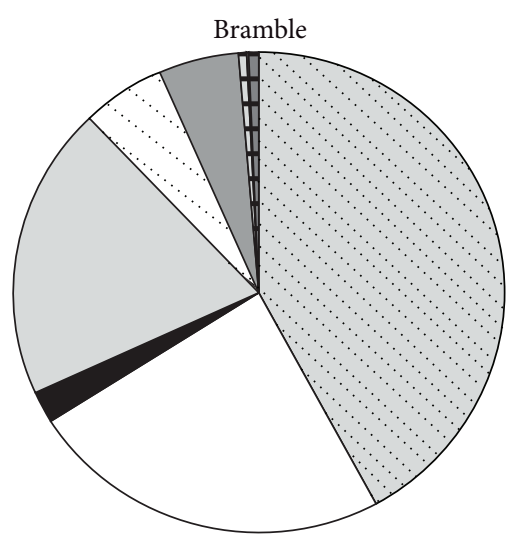

(a)
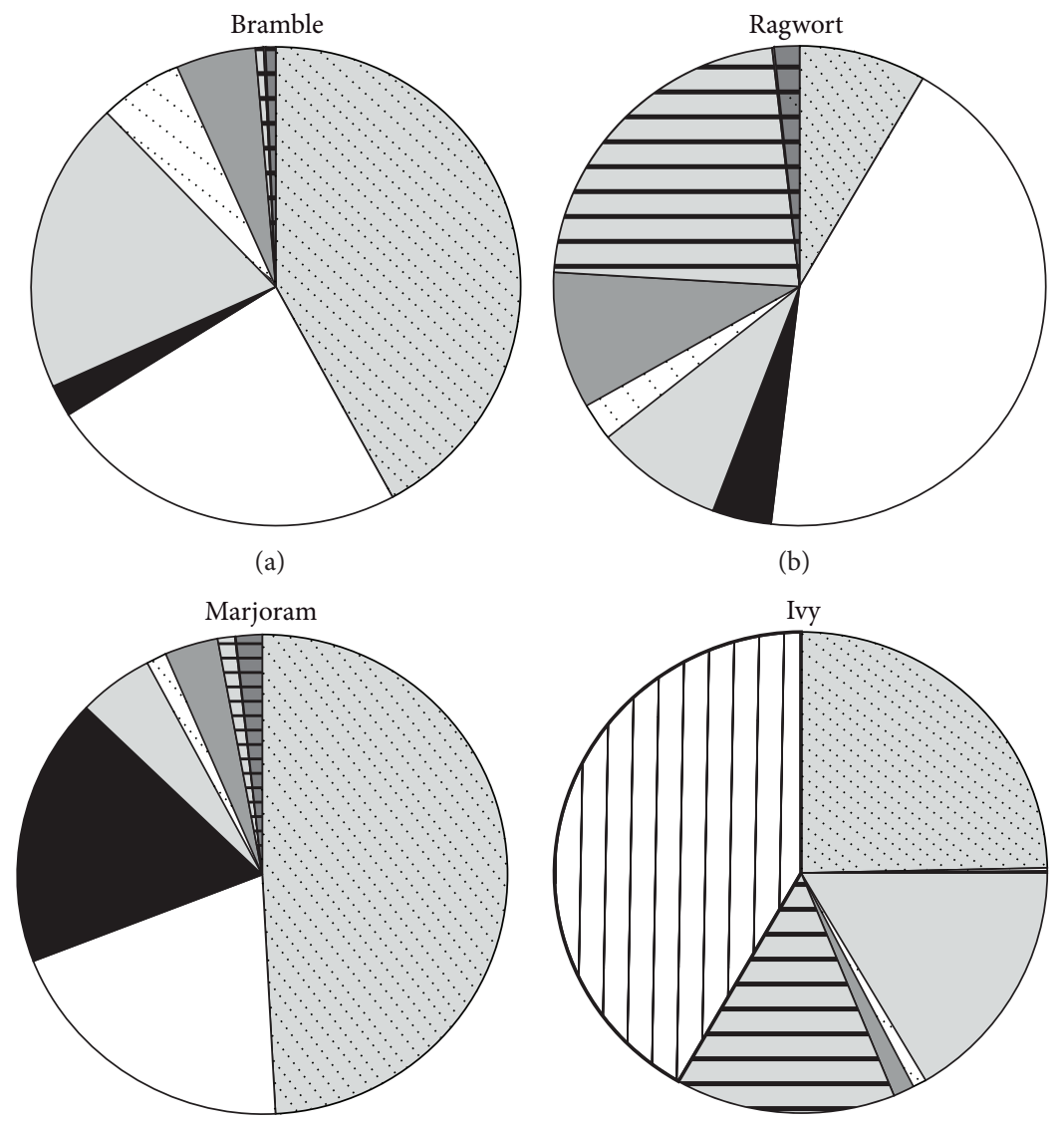

(b)

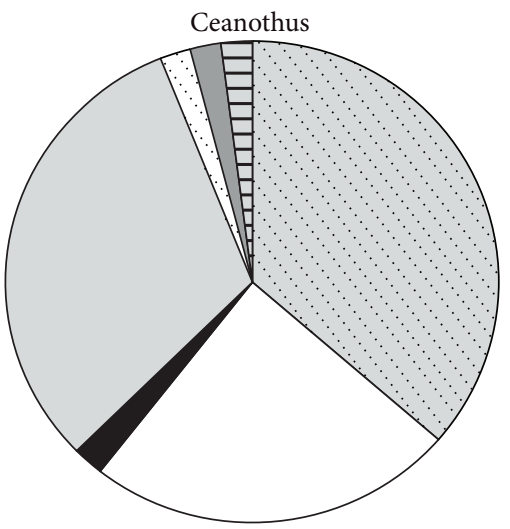

(c)

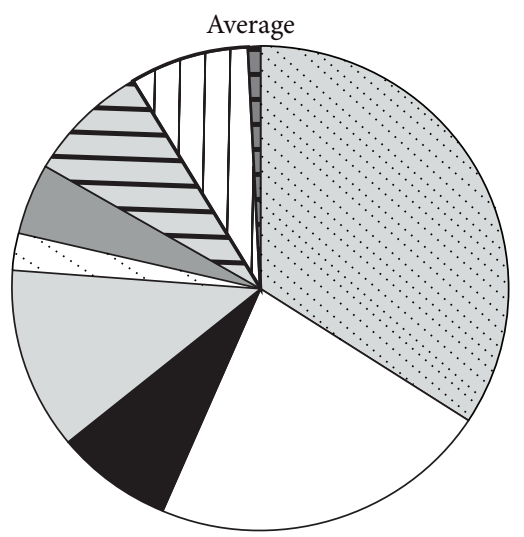

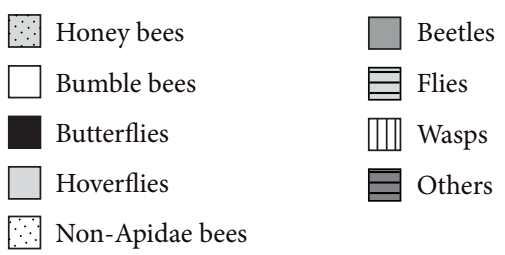

(d) (e)

FIGURE 2: Eight main insect groups were commonly found on all plants in varying proportions. Daily census data were taken on (a) bramble, $n=900$; (b) marjoram, $n=1300$; (c) ragwort, $n=800$; and (d) ivy, $n=700$. California lilac (e) census was inferred from the pilot rate data $(n=99)$. Averages (f) were taken across all the data. The "Others" category, which was infrequent $(<2 \%$ of all collected census data), included ants $(n=6)$, mirid bugs $(n=5)$, a lacewing $(n=1)$, and moths $(n=28)$. Overall we took a census on 37 study days across four plants ( $n=3700$ for bramble, marjoram, ragwort, and ivy plus $n=99$ for California lilac). Honey bees were the most frequent insect observed (34\%), followed by the bumble bees (22\%) and hoverflies (12\%).

were rare enough in the overall census to be combined with others (Figure 2, "Others" category). Census data also additionally included a few ants, bugs (Miridae), and lacewings (Chrysopidae), but these were infrequent, comprising $<2 \%$ of the insects counted, and were also included with moths in the "Others" category (Figure 2).

2.2. Data Collection: Insect Visitation Rate. Data were collected from June 27 to October 30, 2013, on days when the insects were actively foraging (12-31C). The number of days spent collecting data per plant was largely determined by bloom period and days with good weather and was as follows: California lilac: 7; bramble: 18; marjoram: 17; ragwort: 7; ivy: 10. Once an insect was spotted, we would count the number of "flowers" (see above for definitions) probed in one minute, with the stopwatch starting with the first probing. The plants were found in large, adjacent patches (bramble or ivy) or were many plants growing close together (ragwort, marjoram; Figure 1(a)), which aided in our following of the insects. Once we completed a rate count for one insect, we would walk further down the patch or to another plant to find a different insect, which decreases the likelihood of pseudoreplication. Usually it would take nearly an hour to walk down the patches.

We also noted whether, during the one-minute observation period, the insect left the target plant to visit a different, 
neighboring plant species. This was a rare occurrence (12 times over the entire study period, $0.004 \%$ of visits), even though all of our target plant locations were in natural or seminatural landscape (with the exception of the California lilac, which was planted on campus) and amid other flowering plants and trees. Lastly, less data were collected on California lilac $(n=99)$, although we still include these data within the main analysis, as plant is retained as a random factor. In all, we gathered one-minute flower visitation rate data for 2987 insects from the five study plants across the entire study.

2.3. Data Collection: Insect Census. To determine which types of insects were generally present, we also carried out a census of the first 100 insects observed on each plant at the start of every study day. Census-taking was less to determine all the insects that visit plants, where it would be necessary to take time of day into account, and more to obtain a broad picture of insect visitors. Census-taking involved walking slowly through or by the entire plant patch and identifying 100 insects on the flowers. We did not collect formal census data on California lilac because we used this species in the beginning as a pilot before we had agreed upon the methods. However, as we collected $n=99$ rate data points (see above), we used these data to provide a census for California lilac. In all, we counted and categorized 3799 insects (bramble $=900$, marjoram $=1300$, ragwort $=800$, ivy $=700$, and California lilac $=99)$ for the census.

2.4. Data Analysis. For the census data, we report only descriptive statistics as here the main aim was simply to provide a broad picture of the abundance of different insect types per plant species and to show that each plant was visited by a range of insects.

For the differences among insect types in flower visitation rate, which was the main study question, all analyses were done in $\mathrm{R}$ 3.0.2 using the lmer function from the lme 4 package $[28,29]$. We used generalized linear mixed models (GLMMs) with a Poisson error structure. Location and plant species were included as random factors. We tested the response of rate (flower visitation rate) against the fixed factor of insect group ( 9 categories, see Figure 3/Table 1).

Additionally, during data collection, it was clear that there were large differences within the non-Apidae bees. Specifically, we noticed that Megachilidae bees were quicker compared to the others, mostly Halictidae. Within Megachilidae, we were able to identify Osmia bicornis (previously Osmia rufa). Therefore, to investigate further within-group differences, we performed an analysis in which we separated out the non-Apidae bees to Osmia and non-Osmia. Then we used a similar model to test for differences in visitation rate between these two and also compared to honey bees. For both models, we performed necessary corrections for multiple testing [30], and all reported $p$ values are adjusted.

\section{Results}

3.1. Census of Insect Present: A Variety of Insect Visitors Were Found on All 5 Plant Species. Of our nine insect functional
TABLE 1: Summary of rate data showing number of observations, the mean rate, and the post hoc significance. Rows are ordered according to visitation rate. In all, we collected rate data (flowers probed/minute) from 2987 insects.

\begin{tabular}{lccc}
\hline Insect group & $\begin{array}{c}\text { Observations } \\
(n)\end{array}$ & $\begin{array}{c}\text { Mean } \\
\text { rate/minute }\end{array}$ & $\begin{array}{c}\text { Post hoc } \\
\text { significance }\end{array}$ \\
\hline Bumble bees & 524 & 11.5 & $\mathrm{a}$ \\
Honey bees & 808 & 9.2 & $\mathrm{~b}$ \\
Non-Apidae & 114 & 5.2 & $\mathrm{c}$ \\
bees & 479 & 4.8 & $\mathrm{~d}$ \\
Hoverflies & 128 & 4.3 & $\mathrm{e}$ \\
Wasps & 668 & 3.9 & $\mathrm{f}$ \\
Butterflies & 52 & 3.4 & $\mathrm{gf}$ \\
Flies (others) & 81 & 3.2 & $\mathrm{~g}$ \\
Moths & 133 & 2.2 & $\mathrm{~h}$ \\
Beetles & & &
\end{tabular}

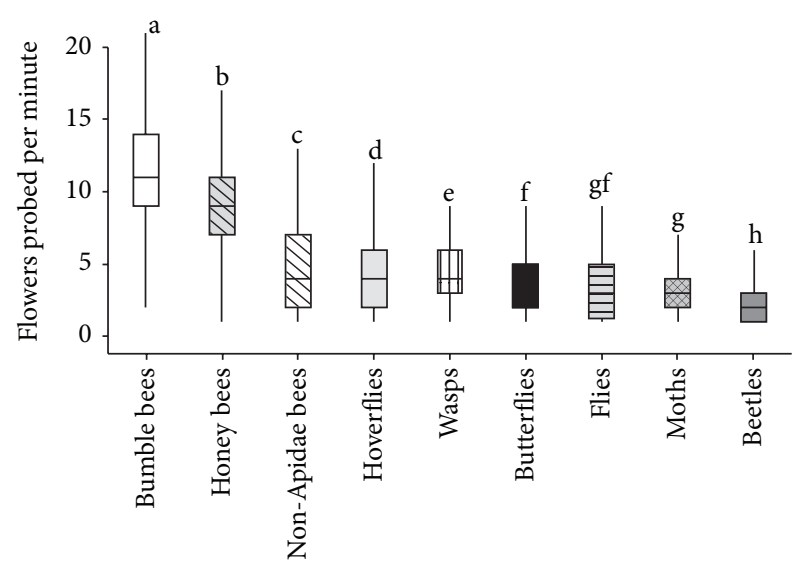

FIGURE 3: Insect pollinator groups significantly differ in the rate at which they probe flowers. Bumble bees (11.5 flowers/minute) and honey bees ( 9.2 flowers/minute) have the quickest rate of flower visitation, whereas beetles are the slowest ( 2.2 flowers/minute). Letters display post hoc results, where groups that share letters do not significantly differ. All pairwise comparisons significantly differed from each other, with the exception of flies and butterflies as well as flies and moths. Groups are ranked according to their flower probing rate. Box lines report medians and lower and upper quartiles, and whiskers extend either to maximum or minimum data points or to 1.5 times the interquartile range.

groups, we found eight (honey bees, bumble bees, butterflies, hoverflies, non-Apidae bees, beetles, flies, and wasps) in abundance on all five plants in varying proportions $(n=$ 3799, Figure 2). There was some seasonal effect. For example, wasps (most are Vespidae) are most common on ivy, which blooms in autumn, presumably because their colonies reach maximum population at this time of year [31]. In contrast, bumble bees were not abundant on ivy, as their colonies generally die out in late summer [32]. The honey bee was the most abundant insect overall in the census (34\%), followed by bumble bees (22\%) and hoverflies (12\%; Figure $2(\mathrm{f})$ ). 


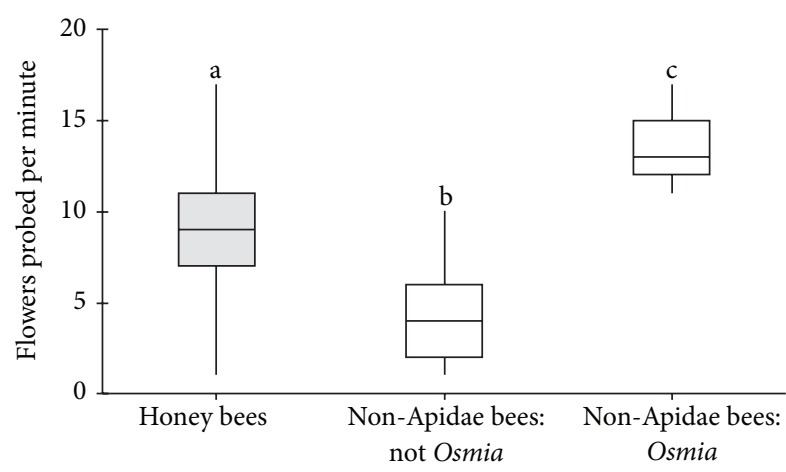

FIGURE 4: Osmia spp. visit significantly more flowers (13.4/minute) than other non-Osmia solitary bees (4.3/minute) and honey bees (9.2/minute). Letters display post hoc results, where groups that share letters do not significantly differ. Box lines report medians, and whiskers extend either to maximum or minimum data points or to their 1.5 times the interquartile range.

\subsection{Insect Groups Differ Significantly in Their Flower Probing} Rates, regardless of Plant. There was a highly significant effect of insect group on rate $(n=2987$; Table 1, Figure 3, GLMM with group as fixed factor compared to the null model GLMM without group, $\chi^{2}=3896.2, \mathrm{df}=8$, and $\left.P<2.2 e^{-16}\right)$. The mean rate ranged from bumble bees (11.5 flowers/minute) to beetles ( 2.2 flowers/minute; Table 1$)$. Post hoc analysis revealed that all pairwise comparisons were significantly different from each other except between butterflies and flies as well as flies and moths (Figure 3). Location and plant explained little of the variance (0.011 and 0.062 , resp.), although we retained them as random factors in the model.

\subsection{Osmia spp. Have a Significantly Faster Flower Visitation} Rate Than Other Non-Apidae Bees. When we looked specifically at Osmia, we found a highly significant effect of group (Apis, non-Apidae: not Osmia, and non-Apidae: Osmia) on rate (Figure 4, GLMM with group as fixed factor compared to null model without group, $\left.P<2.2 e^{-16}\right)$. Osmia spp. had a higher rate (13.4 flowers/minute) than honey bees (9.2 flowers/min) and other non-Osmia non-Apidae bees (4.3 flowers/minute).

\section{Discussion}

Over 500 years ago, Geoffrey Chaucer coined the phrase "as busy as bees" in his Canterbury Tales. Centuries on, our results confirm that this widely accepted expression is in fact true regarding bee foraging behavior. Bees, especially the numerically abundant Apidae bees, visited many more flowers per minute than other types of insects. The bumble bees, as the quickest visitors (11.5 flowers/minute), were over five times faster than the beetles, which were the slowest (2.2 flowers/minute; Figure 3, Table 1). This is in agreement with previous work demonstrating that hymenopterans were quicker than lepidopterans or dipterans in their visitation rates on one plant, lavender, in a study that described interspecific patterns of plant-pollinator interactions [2]. Our results span five different plant species and describe what may be a general phenomenon, although this will need confirmation with additional studies in other countries and climates and on different insects within each category (e.g., stingless bees).

However, not all bees were busy. Within the non-Apidae bees, while Osmia spp. had a speedy 13.4 flowers/minute rate, the other non-Osmia non-Apidae bees visited 4.3 flowers/minute (Figure 4). Many of the slower non-Osmia nonApidae bees were quite small, mainly of the family Halictidae. Further research could determine if there are consistent differences in visitation rate between the two families. The quickness of Osmia is especially interesting because the genus is often suggested as a good wild bee pollinator for orchards. Osmia are possible to manage and also have a short flight range, which means they will not stray far when placed in an orchard, and are tolerant of nonideal weather conditions, like wind and light rain $[8,33-35]$. Here we show that Osmia also possesses a quick flower visitation rate, which has previously been reported for berry pollination [35] and may also help them to be effective pollinators.

In our study, we did not control for temperature, which influences the activity levels of insects. However, our census data shows that most insects were found on most plants, which bloomed successively from summer to autumn. Our analysis kept plant as a random factor, and still there was a significant effect of insect group on rate.

Our plants were a mixture of self-compatible ones (bramble and marjoram [36-38]), self-incompatible ones [39], or a mixture of both/unknown [37, 40]. Additionally, during our study sometimes the insects visited multiple flowers on the same plants (e.g., California lilac), and sometimes the insects visited multiple, neighboring plants (ragwort, bramble, and marjoram). Therefore, we cannot calculate a pollination probability per se with these data [41, 42]; however, we have taken an important first step to quantify differences in behavioral patterns, specifically the speed at which different functional insect groups visit flowers. Lastly, pollinator efficiency of course would depend not only on visitation frequency, but also on the total number of visits from a given functional group (e.g., the density of an insect group). Our study, which was observational, demonstrates that insect density for our location varied greatly between functional groups, especially across the seasons (Figure 2), all of which would influence pollination.

Our census data shows that, overall, the honey bee was the most frequent insect found on all the plants (34\% across all plants/locations; Figure 2), which is comparable to reported levels found in previous studies that determined honey bee proportions on spike lavender in Spain (24.8\%) [2] or on garden plants in south England (28\%) [43]. Although abundance will vary with location (i.e., proximity to apiaries of managed honey bee hives) and season, it is important to note that, in this study, only one location (Falmer) was near a known apiary (our laboratory). The study in Spain also reported that the nearest apiary was too far away to contribute significantly 
to their reported honey bee abundance [2]. Rather, honey bees, whose colonies may possess tens of thousands of workers compared to the much smaller colonies of bumble bees or non-Apidae bees, may be just abundant in many Western landscapes. In addition to being abundant in numbers, honey bees are also abundant temporally throughout the foraging season: other insect groups appear in our census, peak, and then demonstrate a decrease in abundance, as dictated by their phenology. In contrast, honey bee colonies possess workers year round and for temperate climates usually have active foraging from early spring until late autumn [44]. Our study began at the end of June with the flowering of California lilac, which was followed by bramble, marjoram, ragwort, and finally ivy, which finished at the end of October. Honey bees were a consistent presence across the study (Figure 2). The honey bee and bumble bee are also in possession of another adaptation that most likely helps in their pollination efficiency. The hairiness of their bodies aides in the transfer in pollen $[13,15,16]$. This morphological adaptation, combined with their abundance and high flower visitation rate and, with honey bees, their long distance foraging [44], plays a role in making Apidae bees very effective pollinators.

Although we did not test why Apidae bees, like bumble bees and honey bees, are speedier as they visit flowers, it is interesting to consider a few options. One reason may be that honey bees and bumble bees only visit flowers to forage, whereas other insects, in addition to foraging, visit flowers to do other things like sun themselves or lay eggs $[45,46]$. More work should be done to quantify and to compare per plant different time spent doing different behaviors per functional insect group. Future studies could investigate the contribution of life history differences on any foraging rate differences and may help our understanding of the complex way in which plants, insects, and environment interact within the process of pollination.

\section{Conflict of Interests}

The authors declare that there is no conflict of interests regarding the publication of this paper.

\section{Acknowledgments}

The authors thank Saskia Walter and Jeremy Dimora for their help collecting data one afternoon. Margaret J. Couvillon is funded by Nineveh Charitable Trust, Tomer J. Czaczkes is funded by an Alexander von Humboldt Postdoctoral Research Scholarship, and Karin L. Alton is funded by Rowse Honey.

\section{References}

[1] R. M. Arnold, "Pollination, predation and seed set in Linaria vulgaris (Scrophulariaceae)," American Midland Naturalist, vol. 107, no. 2, pp. 360-369, 1982.

[2] C. M. Herrera, "Pollinator abundance, morphology, and flower visitation rate: analysis of the 'quantity' component in a plantpollinator system," Oecologia, vol. 80, no. 2, pp. 241-248, 1989.
[3] C. M. Herrera, "Components of pollinator 'quality': comparative analysis of a diverse insect assemblage," Oikos, vol. 50, no. 1, pp. 79-90, 1987.

[4] A. F. Motten, "Reproduction of Erythronium umbilicatum (Liliaceae): pollination success and pollinator effectiveness," Oecologia, vol. 59, no. 2-3, pp. 351-359, 1983.

[5] A. F. Motten, "Pollination ecology of the spring wildflower community of a temperate deciduous forest," Ecological Monographs, vol. 56, no. 1, pp. 21-42, 1986.

[6] K. W. Richards, "Diversity, density, efficiency, and effectiveness of pollinators of cicer milkvetch, Astragalus cicer L.," Canadian Journal of Zoology, vol. 65, no. 9, pp. 2168-2176, 1987.

[7] A. A. Snow and D. W. Roubik, "Pollen deposition and removal by bees visiting two tree species in Panama," Biotropica, vol. 19, no. 1, pp. 57-63, 1987.

[8] N. Vicens and J. Bosch, "Pollinating efficacy of Osmia cornuta and Apis mellifera (Hymenoptera: Megachilidae, Apidae) on 'Red Delicious' apple," Environmental Entomology, vol. 29, no. 2, pp. 235-240, 2000.

[9] R. W. M. U. M. Wanigasekara and W. A. I. P. Karunaratne, "Efficiency of buzzing bees in fruit set and seed set of Solanum violaceum in Sri Lanka," Psyche, vol. 2012, Article ID 231638, 7 pages, 2012.

[10] N. M. Waser, V. M. Price, A. M. Montalvo, and R. N. Gray, "Female mate choice in a perennial herbaceous wildflower, Delphinium nelsonii," Evolutionary Trends in Plants, vol. 1, pp. 29-33, 1987.

[11] J. A. Winsor, L. E. Davis, and A. G. Stephenson, “The relationship between pollen load and fruit maturation and the effect of pollen load on offspring vigor in Cucurbita pepo," The American Naturalist, vol. 129, no. 5, pp. 643-656, 1987.

[12] C. L. Wolin, C. Galen, and L. Watkins, "The breeding system and aspects of pollination effectiveness in Oenothera speciosa (Onagraceae)," The Southwestern Naturalist, vol. 29, no. 1, pp. 15-20, 1984.

[13] G. Ne'Eman, A. Jürgens, L. Newstrom-Lloyd, S. G. Potts, and A. Dafni, "A framework for comparing pollinator performance: effectiveness and efficiency," Biological Reviews, vol. 85, no. 3, pp. 435-451, 2010.

[14] M. Proctor, P. Yeo, and A. Lack, The Natural History of Pollination, HarperCollins, London, UK, 1996.

[15] D. A. Kendall and M. E. Solomon, "Quantities of pollen on the bodies of insects visiting apple blossom," Journal of Applied Ecology, vol. 10, no. 2, pp. 627-634, 1973.

[16] J. B. Free and I. H. Williams, "The transport of pollen on the body hairs of honeybees (Apis mellifera L.) and bumblebees (Bombus spp. L.)," The Journal of Applied Ecology, vol. 9, no. 2, pp. 609-615, 1972.

[17] N. M. Waser, "Flower constancy: definition, cause, and measurement," The American Naturalist, vol. 127, no. 5, pp. 593-603, 1986.

[18] D. P. Vázquez, W. F. Morris, and P. Jordano, "Interaction frequency as a surrogate for the total effect of animal mutualists on plants," Ecology Letters, vol. 8, no. 10, pp. 1088-1094, 2005.

[19] N. J. Balfour, M. Garbuzov, and F. L. W. Ratnieks, "Longer tongues and swifter handling: why do more bumble bees (Bombus spp.) than honey bees (Apis mellifera) forage on lavender (Lavandula spp.)?” Ecological Entomology, vol. 38, no. 4, pp. 323-329, 2013.

[20] D. Goulson, J. C. Stout, S. A. Hawson, and J. A. Allen, "Floral display size in comfrey, Symphytum officinale L. (Boraginaceae): 
relationships with visitation by three bumblebee species and subsequent seed set," Oecologia, vol. 113, no. 4, pp. 502-508, 1998.

[21] O. Jennersten and S. G. Nilsson, "Insect flower visitation frequency and seed production in relation to patch size of Viscaria vulgaris (Caryophyllaceae)," Oikos, vol. 68, no. 2, pp. 283-292, 1993.

[22] T. P. Spira, A. A. Snow, D. F. Whigham, and J. Leak, "Flower visitation, pollen deposition, and pollen-tube competition in Hibiscus moscheutos (Malvaceae)," American Journal of Botany, vol. 79, no. 4, pp. 428-433, 1992.

[23] C. S. Stubbs and F. A. Drummond, "Blueberry and cranberry (Vaccinium spp.) pollination: a comparison of managed and native bee foraging behavior," Acta Horticulturae, vol. 437, pp. 341-344, 1997.

[24] J. D. Thompson, "How do visitation patterns vary among pollinators in relation to floral display and floral design in a generalist pollination system?” Oecologia, vol. 126, no. 3, pp. 386-394, 2001.

[25] J. M. Grindeland, N. Sletvold, and R. A. Ims, "Effects of floral display size and plant density on pollinator visitation rate in a natural population of Digitalis purpurea," Functional Ecology, vol. 19, no. 3, pp. 383-390, 2005.

[26] E. C. Engel and R. E. Irwin, "Linking pollinator visitation rate and pollen receipt," American Journal of Botany, vol. 90, no. 11, pp. 1612-1618, 2003.

[27] N. M. Waser and M. V. Price, "Pollination efficiency and effectiveness of bumble bees and hummingbirds visiting Delphinium nelsonii," Collectanea Botanica, vol. 19, pp. 9-20, 1990.

[28] R Development Core Team, R: A Language and Environment for Statistical Computing, R Foundation for Statistical Computing, Vienna, Austria, 2007.

[29] D. Bates, M. Maechler, B. M. Bolker, and S. Walker, "lme4: Linear mixed-effects models using Eigen and S4," R package version, 2013, http://projecteuclid.org/download/pdf_1/euclid.ss/ 1177011926

[30] Y. Benjamini and Y. Hochberg, "Controlling the false discovery rate: a practical and powerful approach to multiple testing," Journal of the Royal Statistical Society, Series B. Methodological, vol. 57, no. 1, pp. 289-300, 1995.

[31] J. P. Spradbery, Wasps: An Account of the Biology and Natural History of Solitary and Social Wasps, Sidgwick and Jackson, London, UK, 1973.

[32] F. W. L. Sladen, The Humble-Bee, Macmillan, London, UK, 1912.

[33] S. W. Batra, "Bees and pollination in our changing environment," Apidologie, vol. 26, no. 5, pp. 361-370, 1995.

[34] J. Bosch and W. P. Kemp, "Developing and establishing bee, species as crop pollinators: the example of Osmia spp. (Hymenoptera: Megachilidae) and fruit trees," Bulletin of Entomological Research, vol. 92, no. 1, pp. 3-16, 2002.

[35] J. H. Cane, "Pollination potential of the bee Osmia aglaia for cultivated red raspberries and blackberries (Rubus: Rosaceae)," HortScience, vol. 40, no. 6, pp. 1705-1708, 2005.

[36] H. Nybom, "Active self-pollination in blackberries (Rubus subgen. Rubus, Rosaceae)," Nordic Journal of Botany, vol. 5, no. 6, pp. 521-525, 1985.

[37] J. H. Jacobs, S. J. Clark, I. Denholm, D. Goulson, C. Stoate, and J. L. Osborne, "Pollination biology of fruit-bearing hedgerow plants and the role of flower-visiting insects in fruit-set," Annals of Botany, vol. 104, no. 7, pp. 1397-1404, 2009.
[38] J. Dauber, J. C. Biesmeijer, D. Gabriel et al., "Effects of patch size and density on flower visitation and seed set of wild plants: a pan-European approach," Journal of Ecology, vol. 98, no. 1, pp. 188-196, 2010.

[39] D. Cheng, H. Kirk, P. P. J. Mulder, K. Vrieling, and P. G. L. Klinkhamer, "Pyrrolizidine alkaloid variation in shoots and roots of segregating hybrids between Jacobaea vulgaris and Jacobaea aquatica," New Phytologist, vol. 192, no. 4, pp. 10101023, 2011.

[40] B. B. Lamont and D. Wiens, "Are seed set and speciation rates always low among species that resprout after fire, and why?" Evolutionary Ecology, vol. 17, no. 3, pp. 277-292, 2003.

[41] T. J. De Jong, N. M. Waser, and P. G. L. Klinkhamer, "Geitonogamy: the neglected side of selfing," Trends in Ecology \& Evolution, vol. 8, no. 9, pp. 321-325, 1993.

[42] Y. Iwasa, T. J. De Jong, and P. G. Klinkhamer, "Why pollinators visit only a fraction of the open flowers on a plant: the plant's point of view," Journal of Evolutionary Biology, vol. 8, no. 4, pp. 439-453, 1995.

[43] M. Garbuzov and F. L. W. Ratnieks, "Quantifying variation among garden plants in attractiveness to bees and other flowervisiting insects," Functional Ecology, vol. 28, no. 2, pp. 364-374, 2014.

[44] M. J. Couvillon, R. Schürch, and F. L. W. Ratnieks, "Waggle dance distances as integrative indicators of seasonal foraging challenges," PLoS ONE, vol. 9, no. 4, Article ID e93495, 2014.

[45] M. L. Stanton, "Short-term learning and the searching accuracy of egg-laying butterflies," Animal Behaviour, vol. 32, no. 1, pp. $33-40,1984$

[46] C. W. Clark and R. Dukas, "Balancing foraging and antipredator demands: an advantage of sociality," The American Naturalist, vol. 144 , no. 3, pp. 542-548, 1994. 

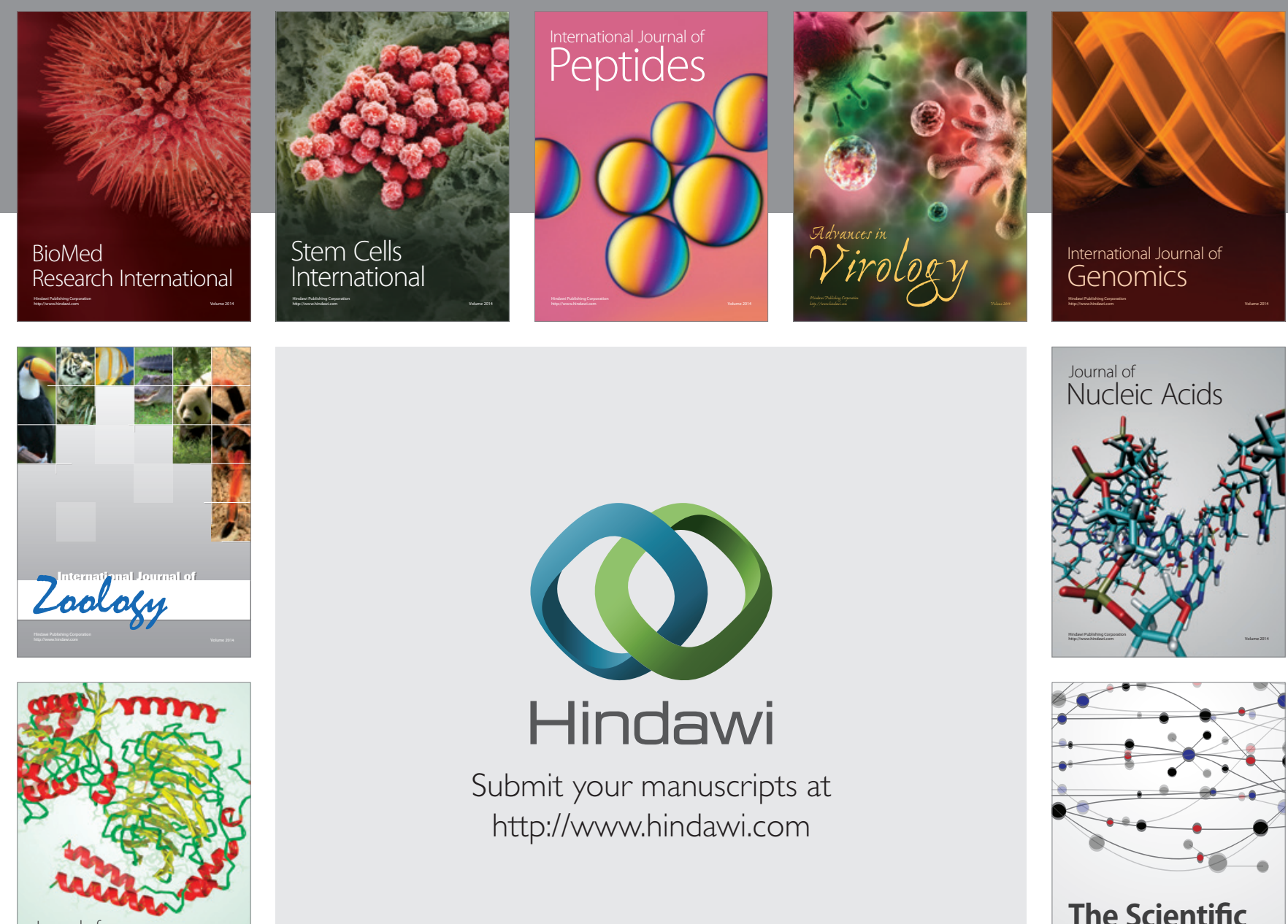

Submit your manuscripts at

http://www.hindawi.com

Journal of
Signal Transduction
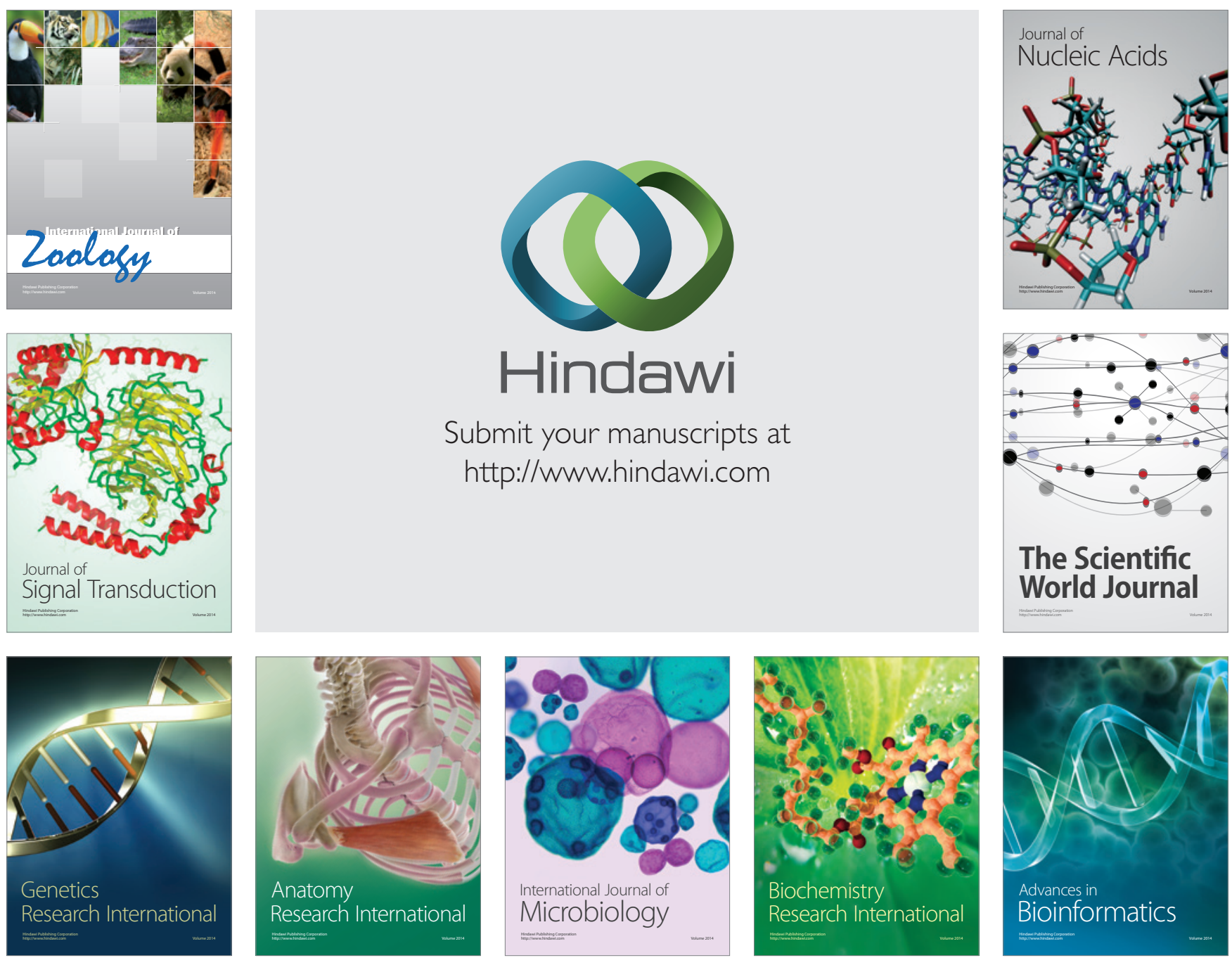

The Scientific World Journal
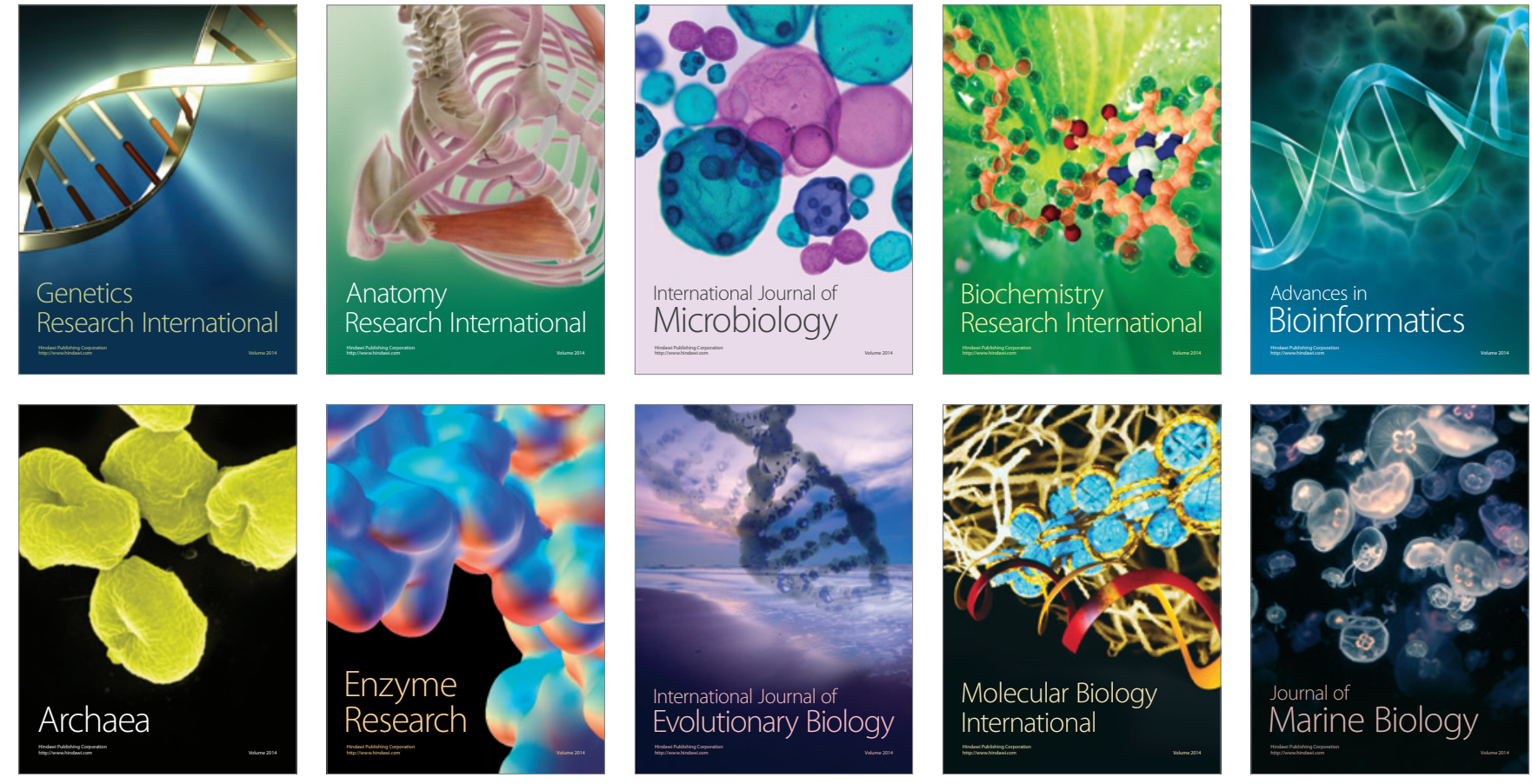